\title{
TEKNIK PENANGANAN DAN CEMARAN MIKROBA PADA IKAN LAYANG SEGAR DI PASAR TRADISIONAL KOTA AMBON
}

\author{
Edir Lokollo*dan Meigy Nelce Mailoa \\ Program Studi Teknologi Hasil Perikanan, Fakultas Perikanan dan Ilmu Kelautan, \\ Universitas Pattimura, Kampus Unpatti-Poka \\ Jalan Mr. Chr. Soplanit Poka 97233 Ambon Maluku \\ Telepon. (0911) 3825060, faks. (0911) 3825061 \\ *Korespondensi : edir.lokollo@ymail.com \\ Diterima 13 Maret 2019/30 April 2020
}

Cara sitasi: Lokollo E, Mailoa MN. 2020. Teknik penanganan dan cemaran mikroba pada ikan layang segar di pasar tradisional Kota Ambon. Jurnal Pengolahan Hasil Perikanan Indonesia. 21(3): 103-111.

\begin{abstract}
Abstrak
Hasil perikanan merupakan produk yang mudah mengalami kebusukan, sehingga diperlukan teknik penanganan yang cermat dan tepat untuk mempertahankan mutunya. Penelitian ini bertujuan untuk membuktikan dampak penanganan ikan layang yang dijual di pasar. Ikan layang diambil secara acak di Pasar Arumbae dan Pasar Batu Merah Kota Ambon dua kali dalam sehari yakni pada waktu pagi dan waktu sore hari. Teknik penanganan ikan diamati pada saat distribusi dan penanganan di pasar yang meliputi pembersihan, penyimpanan, peletakan ikan serta pemberian es. Jumlah cemaran mikroba pada sampel dihitung menggunakan metode total plate count (TPC). Hasil penelitian menunjukkan bahwa jumlah cemaran mikroba pada ikan yang diambil pada pagi hari lebih rendah dibandingkan pada ikan yang diambil pada sore hari. Teknik penanganan dan penjajakan ikan layang yang diterapkan oleh para pedagang di Pasar Arumbae dan Batu Merah belum diterapkan dengan baik dan belum memperhatikan sistem rantai dingin, sanitasi air, dan tempat penyimpanan ikan selama penjualan. Jumlah cemaran mikroba pada ikan layang

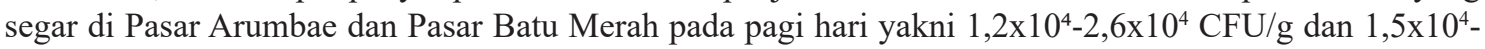
$2,6 \times 10^{4} \mathrm{CFU} / \mathrm{g}$ sedangkan pada sore hari yaitu $2,4 \times 10^{4}-5,0 \times 10^{5} \mathrm{CFU} / \mathrm{g}$ dan $4,9 \times 10^{4}-4,6 \times 10^{5} \mathrm{CFU} / \mathrm{g}$. Jumlah mikroba pada ikan layang segar di pasar tradisional Kota Ambon masih sesuai standar mutu mikrobiologi ikan segar yaitu maksimal $5 \times 10^{5} \mathrm{CFU} / \mathrm{g}$.
\end{abstract}

Kata kunci : pencucian, pendinginan, penyimpanan ikan, total plate count

\section{Handling techniques and Microbial Contamination on Fresh Scads Fish (Decapterus sp) in Traditional Markets, Ambon City}

\begin{abstract}
Fishery products is a highly perishable product experiencing rapid quality deterioration. Proper handling techniques are needed to maintain the quality of fisheries products. This study was aimed to assess the handling technique of scad fish in markets of Ambon City. The Scad fish were randomly obtained from Arumbae and Batu Merah Market, Ambon City twice a day, morning and evening. Fish handling techniques were observed during distribution and handling in the market which included cleaning, storing, laying fish and giving ice. Microbial contamination was determined using the total plate count (TPC) method. The study found that the levels of microbial contamination in fish taken in the morning were lower than in the fish taken in the afternoon. The handling and assessment techniques of flying fish which are applied by traders in the Arumbae and Batu Merah Markets have not been implemented well and not yet paying attention to the cold chain system, water sanitation, fish storage during sales The number of microbial contamination in fresh scads fish in the Arumbae and Batu Merah market in the morning was $1.2 \times 10^{4}-2.6 \times 10^{4} \mathrm{CFU} / \mathrm{g}$ and $1.5 \times 10^{4}-2.6 \times 10^{4}$ $\mathrm{CFU} / \mathrm{g}$ while in the afternoon it is $2.4 \times 10^{4}-5.0 \times 10^{5} \mathrm{CFU} / \mathrm{g}$ and $4.9 \times 10^{4}-4.6 \times 10^{5} \mathrm{CFU} / \mathrm{g}$. These numbers are still below the maximum allowed level, i.e $5 \times 10^{5} \mathrm{CFU} / \mathrm{g}$, suggesting that the fish are safe for consumption.
\end{abstract}

Keywords: chilling, fish storage, total plate count, washing 


\section{PENDAHULUAN}

Ikan pelagis kecil di antaranya layang (Decapterus sp), selar (Selaroides spp), kembung (Rastrellinger spp), tongkol (Auxis thazard) merupakan sumberdaya perikanan yang sangat potensi di Kota Ambon. Alat tangkap yang biasa digunakan oleh nelayan untuk menangkap ikan tersebut yaitu "jaring bobo" (Apituley et al. 2017). Ikan bila tidak ditangani dengan baik maka akan mengalami pembusukan sehingga menurunkan kualitasnya. Penurunan mutu ikan terjadi setelah ikan mati dan yang paling dominan dan berperan dalam kerusakan ataupun pembusukan ikan adalah bakteri. Menurut Sembayang (2002); Susanto dan Sopiah (2003) pembusukan yang terjadi pada bagian-bagian tubuh ikan akan mengakibatkan perubahan bau (odor), rupa (appearance) dan tekstur (texture) disebabkan oleh aktivitas mikroba.

Penurunan mutu ikan dapat diketahui melalui perubahan secara organoleptik yang berasal dari produk tersebut (Winarni et al. 2003). Sistem pertahanan tubuh ikan ketika hidup dapat menekan keberadaan bakteri pada daging ikan, namun setelah mekanisme di dalam tubuh ikan terhenti bakteri berkembangbiak dan berpenetrasi ke dalam daging ikan. Penanganan yang terlambat membuat pertumbuhan bakteri semakin pesat sehingga ikan menjadi busuk yang ditandai dengan permukaan tubuh berlendir, daging menjadi lembek, dan berbau busuk dari senyawa antara lain: indol,skatol, merkaptan, am monia, asam sulfida, dan lain-lain. Hadiwiyoto (1993) menjelaskan golongan bakteri psikrofilik dapat mengkontaminasi produk perikanan yang disimpan pada suhu rendah sekitar $1520^{\circ} \mathrm{C}$ dan mampu bertahan hidup pada suhu $-10^{\circ} \mathrm{C}$ hingga $40^{\circ} \mathrm{C}$. Tapotubun et al. (2016) menyatakan bahwa ikan segar dapat terkontaminasi bakteri patogen penyebab penyakit segera setelah ikan ditangkap sampai menjelang konsumsi.

Beberapa kajian tentang cemaran bakteri pada ikan dan hasil laut telah banyak dilakukan dan dilaporkan, Violentina et al. (2015) telah berhasil mengidentifikasi bakteri pada ikan tongkol yang dijual di pasar ikan Kedonganan Bali; Puri (2016) menganalisis aspek mikrobiologis dan sensoris ikan tongkol yang dijual di tempat pemasaran tradisional, modern serta serta gudang pelelangan ikan di Kota Bandar Lampung; Apriani et al. (2017) melaporkan keberadaan mikroba dan nilai sensoris ikan tongkol yang diambil dari pasar Peunoyang dan TPI Lampulo Kota Aceh; Pattipeilohy dan Moniharapon (2016) juga telah melaporkan kemunduran mutu sensoris ikan layang pasca penangkapan.

Mutu ikan segar sebagai bahan baku makanan sangat dipengaruhi oleh teknik penanganannya (Afrianto dan Liviawaty 1989). Pattipeilohy et al. (2010) menjelaskan bahwa penanganan ikan segar (pelagis kecil sampai sedang) pasca tangkap oleh para nelayan purse seine (giob) sampai ke pusat pendaratan yang ada di kota Ambon (Seri/Eri, Waai dan Hitu) selama ini hanya menggunakan es batu sebagai pengawet, bahkan tanpa pengawetan karena ketidaktersediaan es sehingga dapat menurunkan mutu kesegaran ikan, selain itu waktu pembongkaran ikan bila sampai di pasar juga tidak menentu. Kajian terkait efek cara menangani ikan segar oleh pedagang ikan di tempat pemasaran tradisional hingga saat ini masih jarang dilakukan dan yang merujuk khusus penangananan ikan layang selama penjajakan/penjualan di pasar yang berdampak pada jumlah kontaminasi mikroba belum menjadi perhatian yang serius oleh para peneliti, sehingga penelitian ini dilakukan untuk membuktikan dampak teknik penanganan ikan layang terhadap tingkat cemaran mikroba selama penjualan di pasar kota Ambon, agar dapat diambil langkah lebih lanjut untuk perbaikan teknik penanganan.

\section{BAHAN DAN METODE Bahan dan Alat}

Bahan utama pada penelitian ini adalah ikan layang yang dibeli dari pasar Arumbae dan pasar Batu Merah, $\mathrm{NaCl}$ 0,9\%, Plate Count Agar (PCA) (Merck), akuades dan alkohol.

Alat yang digunakan yaitu gelas Erlenmeyer (Duran-Normax, Jerman), gelas beker (Duran-Normax, Jerman), autoklaf (Autoklaf All American 75X), label, timbangan analitik (Top Balance SI 6002), tabung reaksi (Duran-Normax, Jerman), dan rak tabung 
stainless, cawan petri (Duran-Normax, Jerman), inkubator (Isuzu Incubator; SSJ-115), oven (Memmert), mikropipet (Mikropipet Scilogex 1000-5000 uL / 1-5 $\mathrm{mL}$ ), spiritus, pisau kecil, tisu, talenan, spatula stainless dan cool box (stirofoam) dan plastik steril (PP) untuk mengambil sampel.

\section{Metode Penelitian}

Metode pengumpulan data dilakukan dengan metode survei di lapangan untuk mengamatisecaralangsung teknikpenanganan ikan oleh pedagang di pasar yaitu sumber air yang digunakan, es, tempat penyimpanan ikan selama penjualan dan metode eksploratif untuk mengetahui cemaran bakteri pada ikan yang ditumbuhkan pada media agar.

\section{Prosedur Penelitian}

Pengambilan sampel ikan dari pedagang di Pasar Arumbae dan Pasar Batu Merah dilakukan dua kali dalam sehari, yakni pada pagi hari (pukul 07.00-08.00 WIT) dan sore hari (pukul 15.00-16.00 WIT), setiap pengambilan sampel dilakukan pada hari yang sama. Ikan disimpan dalam coolbox kemudian dibawa ke Laboratorium BARISTAN Ambon, untuk selanjutnya dilakukan pengamatan jumlah cemaran mikroba menggunakan metode angka lempeng total.

\section{Total Plate Count (TPC)}

Penghitungan Total Plate Count (TPC) pada ikan layang segar menggunakan metode hitung cawan merujuk pada SNI 01.2332.32006 (BSN 2006).

\section{Analisis Data}

Metode analisis yang digunakan dalam penelitian ini adalah deskriptif kualitatif, data yang dihasilkan dianalisis secara deskriptif serta hasilnya ditampilkan dalam bentuk gambar dan tabel.

\section{HASIL DAN PEMBAHASAN Penanganan Ikan di Pasar Arumbae dan Pasar Batu Merah}

Hasil penelitian menunjukkan bahwa cara penanganan ikan yang dilakukan oleh pedagang di pasar antara lain :

\section{Penanganan ikan selama distribusi}

Hasil tangkapan dari nelayan di bawah ke pasar Arumbae dan pasar Batu Merah menggunakan mobil pick up yang dilengkapi dengan kotak pendingin dan loyang untuk penampung ikan dan tiba di pasar pada pukul 06:00 WIT. Berdasarkan hasil pengamatan di lapangan diketahui bahwa penanganan ikan masih kurang baik, karena masih ditemui pedagang meletakan ikan pada bak mobil pick up yang kotor dan pemberian es tidak memperhitungkan volume ikan. Hal tersebut dapat menyebabkan terjadinya kontaminasi oleh mikroorganisme patogen. Menurut Metusalach et al. (2012) untuk mempertahankan kesegaran ikan maka rasio es dan ikan yang digunakan oleh pedagang selama proses pemasaran yaitu 1:1. Menurut Dwiyitno (2010) ikan dapat terkontaminasi bakteri patogen pada saat penyimpanan maupun selama distribusi dan menyebabkan penyakit bagi yang mengkonsumsinya. Jenis bakteri patogen yaitu Escherichia coli, Salmonella sp. dan Vibrio cholerae ditetapkan sebagai syarat keamanan pangan ikan segar (BSN 2006).

\section{Penanganan ikan oleh para penjual di pasar Arumbae dan pasar Batu Merah}

Penanganan ikan segar yang memengaruhi kualitas merupakan bagian penting pada rantai industri perikanan. Hasil penelitian menunjukkan bahwa cara penanganan ikan yang dipraktikan di tempat pemasaran oleh para pedagang ikan meliputi :

\section{Pembersihan ikan}

Tahap awal yang dilakukan oleh para pedagang sebelum ikan dijual yaitu membersihkan ikan menggunakan air laut dari perairan sekitar pasar. Tempat pengambilan air laut dapat dilihat pada Figure 1.

Penjual ikan melakukan proses pembersihan ikan dengan memasukkan ikan ke dalam ember atau loyang berisi air kemudian dibilas ulang hingga bersih. Praktek penanganan buruk yang biasa dilakukan oleh para penjual ikan pada proses pencucian ikan, yaitu air sisa cucian ikan dibuang begitu saja pada lantai gedung pasar sehingga 
mengakibatkan timbulnya bau busuk dan lantai yang kotor. Menurut Buton et al. (2017) ikan yang dicuci dengan air laut tidak cepat busuk bila dibandingkan dengan ikan yang dicuci dengan air tawar, tetapi air laut yang digunakan harus bersih dan sebelum dipakai sebaiknya ditampung terlebih dahulu untuk mengeluarkan partikel-partikel yang ada pada air laut tersebut. Kapisa et al. (2014) menegaskan bahwa air yang digunakan untuk mencuci ikan harus memenuhi syarat mikrobiologis yaitu bebas bakteri patogen dan untuk mencegah penurunan mutu ikan maka air yang digunakan sebaiknya sudah mengalami proses klorinasi. Laksmi (1988) menyatakan bahwa bakteri Salmonella, Shigella, Vibrio cholera, dan Escherichia coli merupakan bakteri patogen yang berasal dari air. Potensi bakteri patogen yang bersumber dari air dapat menjadi sumber kontaminan pada ikan, oleh sebab itu para pedagang ikan di pasar harus memperhatikan kualitas air pencucian yang digunakan. Apelabi et al. (2014) melaporkan temuan bakteri Salmonella pada air pencucian ikan di pasar di tempat pelelangan ikan kota Kupang. Kapisa et al. (2014) melaporkan terdapat bakteri E. coli pada air pencucian ikan di pasar bahu Kota Manado. Hal ini menunjukkan bahwa kualitas air yang digunakan untuk penanganan pencucian ikan maupun hasil laut juga dapat memengaruhi keberadaan bakteri ikan selama penjualan di pasar.

\section{Proses penyimpanan ikan}

Prosedur penyimpanan ikan dilakukan dengan cara ikan dicuci bersih selanjutnya disimpan dalam peti pendingin berisi es supaya ikan menjadi awet, namun kondisi tempat penyimpanan ikan masih belum sesuai dengan praktek penanganan yang baik misalnya dengan penggunaan kulkas rusak sebagai kotak pendingin untuk menyimpan yang masih dalam keadaan kotor (Figure 2). Litaay et al. (2017) menyatakan teknik penanganan ikan yang baik dengan memperhatikan penerapan sistem rantai dingin serta mengutamakan aspek sanitasi dan higiene, penanganan ikan segar diupayakan dengan menjaga temperatur dingin sekitar $0^{\circ} \mathrm{C}$ dan selalu mempertahankan jumlah es dan tidak terkena sinar matahari. Apabila ikan yang dibiarkan terbuka pada tempat penjualan maka dapat memicu kontaminasi mikroba pada ikan melalui kontak dengan udara dan kontaminan lainnya yang berasal dari asal lingkungan pasar ikan. Kondisi suhu penyimpanan ikan juga merupakan faktor penentu untuk menekan pertumbuhan mikroba sehingga nilai total mikroba pada ikan layang tidak melebihi batas maksimum nilai TPC pada ikan segar.

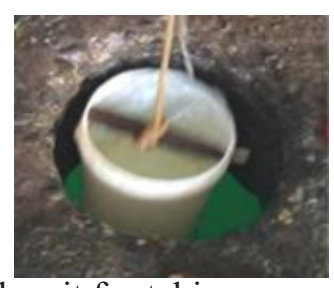

(a) The pit for taking sea water

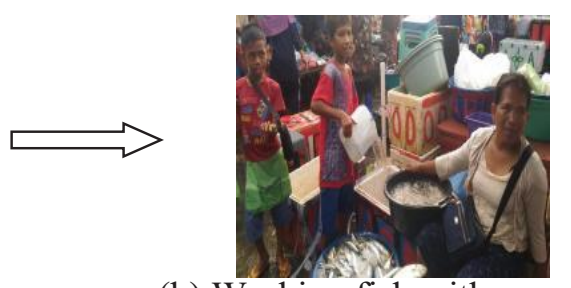

(b) Washing fish with seawater

Figure 1. A place for seawater collection to wash fish.
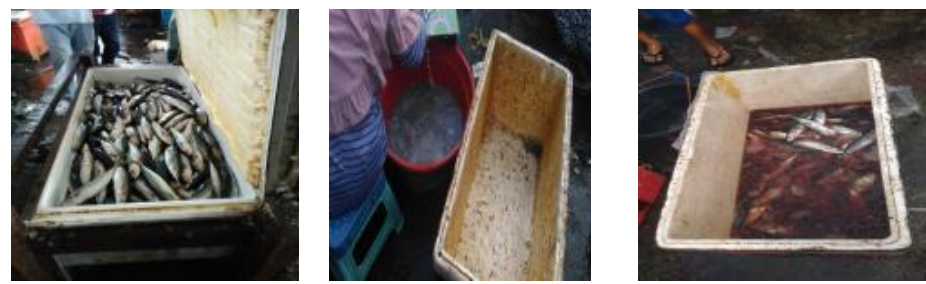

Figure 2 Fish storage box 


\section{Peletakan ikan di meja/loyang penjualan}

Proses pemajangan ikan diatas meja penjualan masih juga di temui hal yang tidak sesuai misalnya menggunakan coolbox kotor, meja kayu untuk tatakan ikan (Figure 3). Andiny (2017) menegaskan meja yang digunakan oleh pedagang sebaiknya memperhatikan tingkat kemiringan meja $\left(3^{\circ}\right)$ dan bahan meja seperti porselin atau kayu yang dilapisi alumunium sehingga mudah untuk dibersihkan. Prihatminingtyas dan Setyowati, (2018) menyatakan bahwa biasanya tidak semua ikan yang dipasarkan dipajang sehingga dibutuhkan kotak pendingin berbentuk sterofoam box atau fiberglass container, untuk menyimpan sisa ikan bila tidak terjual.

\section{Pemberian es}

Ikan harus terus diberi es untuk menjaga rantai dinginnya sehingga memperlambat kemunduran mutunya. Berdasarkan hasil survei para penjual ikan memberikan es tidak memperhatikan jumlah ikan yang ada sehingga kesegaran ikan kurang begitu terjaga. Metusalach et al. (2012) menyatakan bahwa sebaiknya rasio dari ikan dan es yang digunakan selama proses pemasaran yaitu 1:1 dan mempertahankan temperatur $0^{\circ} \mathrm{C}$. Berdasarkan hasil pengamatan langsung terhadap cara penanganan ikan yang dilakukan selama penjualan baik dari proses pembersihan ikan, penyimpanan ikan dan penjajaan ikan, maupun proses pemberian es, sehingga dapat dilihat bahwa cara penanganan ikan oleh pedagang di pasar belum diterapkan dengan baik. Hal ini terbukti lewat praktik yang kurang baik yaitu 1) air pencucian ikan yang dibuang saja ke lantai gedung pasar sehingga menimbulkan bau busuk dan kotor; 2) coolbox dari kulkas bekas digunakan sebagai tempat penyimpanan ikan; 3) Pemberian es di coolbox hanya diberikan seadanya, tidak memperhitungkan banyaknya ikan yang ada.

Panai et al. (2013) menyatakan bahwa penerapan rantai dingin dapat membantu mempertahankan kesegaran ikan. Sitakar et al. (2016) menjelaskan bahwa pendinginan merupakan proses pengawetan dengan suhu rendah yang dapat memperpanjang masa simpan ikan.

Teknik penanganan berperan penting dalam mempertahankan tingkat kesegaran ikan sehingga dapat meminimalisasi adanya perbedaan kualitas ikan dari pemasok yang sama, oleh karena itu dalam proses pemasaran/penjajakan ikan di pasar maka es merupakan komponen penting yang harus terpenuhi. Syafitri et al. (2016) menyatakan bahwa teknik penanganan ikan dengan cara pendinginan dengan perbandingan es dan ikan yaitu 1:1 sangat efektif untuk mempertahankan suhu $0^{\circ} \mathrm{C}$ sehingga mutu ikan dapat dipertahankan selama penjualan.

\section{Total Cemaran Mikroba}

Total cemaran mikroba pada ikan layang (Decapterus sp) yang diambil dari pasar tradisional di kota Ambon dapat dilihat pada Table 1. Kuantitas cemaran mikroba pada sampel ikan yang diambil dari pasar Arumbae pada pagi hari yakni $1,2 \times 10^{4}-2,6 \times 10^{4} \mathrm{CFU} / \mathrm{g}$ dan sampel ikan yang diambil sore hari yaitu $2,4 \times 10^{4}-5,0 \times 10^{5} \mathrm{CFU} / \mathrm{g}$. Total mikroba pada contoh ikan yang diamati dari pasar Batu merah pada pagi hari yakni $1,5 \times 10^{4}-2,6 \times 10^{4}$ $\mathrm{CFU} / \mathrm{g}$ sedangkan pada sampel yang diambil sore hari yaitu $4,9 \times 10^{4}-4,6 \times 10^{5} \mathrm{CFU} / \mathrm{g}$.

Total cemaran mikroba pada ikan yang dipasarkan pada pagi hari jumlahnya masih kecil dibandingkan sampel ikan yang diambil pada sore hari, karena kondisinya yang masih segar, hal ini disebabkan adanya kemunduran
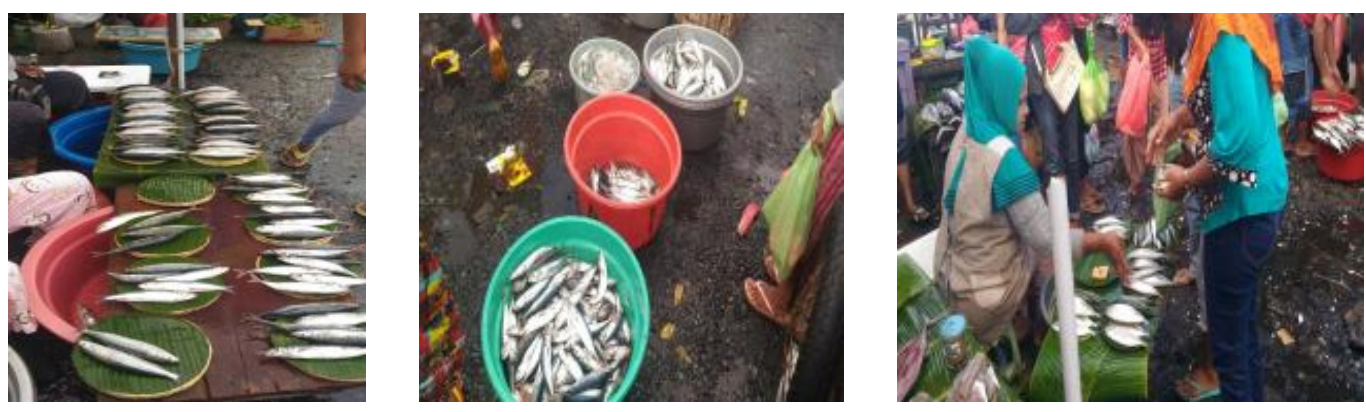

Figure 3 Placing fish for sales 
Table 1 Total plate count of scads fish from traditional markets in Ambon City

\begin{tabular}{cccc}
\hline Sampling Place & Sample & Sampling time & $\begin{array}{c}\text { Total Microbes } \\
(\text { CFU/g) }\end{array}$ \\
\hline & AR1 & & $2.6 \times 10^{4}$ \\
Arumbae & AR2 & Morning & $1.6 \times 10^{4}$ \\
Market (AR) & AR4 & & $1.2 \times 10^{4}$ \\
& AR5 & Afternoon & $5.0 \times 10^{5}$ \\
& AR6 & & $2.4 \times 10^{4}$ \\
& BM1 & & $3.9 \times 10^{4}$ \\
Batu Merah & BM2 & Morning & $2.5 \times 10^{4}$ \\
Market (BM) & BM3 & & $1.5 \times 10^{4}$ \\
& BM4 & & $2.6 \times 10^{4}$ \\
& BM5 & Afternoon & $4.6 \times 10^{5}$ \\
& BM6 & & $5.4 \times 10^{4}$ \\
& & & $4.9 \times 10^{4}$ \\
\hline
\end{tabular}

mutu ikan selama proses penjualan. Ikan mudah rusak sehingga diperlukan penanganan yang memadai agar mutu dan kualitasnya tetap terjaga. Penurunan kualitas ikan dapat dipicu oleh faktor internal misalnya reaksi enzimatis dan faktor eksternal disebabkan oleh parasit atau bakteri. Penurunan mutu ikan dapat terjadi akibat beberapa mekanisme yakni autolisis, aktivitas bakteriologi dan reaksi oksidasi. Husni dan Putra (2015) menegaskan bahwa kerusakan ikan oleh aktivitas bakteri karena jumlah bakteri meningkat karena terus berkembang sehingga menyebabkan pembusukan yang ditandai dengan timbulnya bau busuk dan tekstur daging tidak kompak lagi. Kurniawan et al. (2012) melaporkan bahwa ikan cepat mengalami proses pembusukan jika dibiarkan pada suhu kamar karena komponen air yang besar pada daging ikan sehingga merupakan tempat yang baik bagi perkembangan mikroba pembusuk. Penanganan ikan berfungsi baik untuk mempertahankan kualitas produk dan nilai ekonomi yang dimilikinya (Junianto 2002). Pertumbuhan mikroorganisme dipengaruhi oleh suhu penyimpanan pasca tangkap maupun selama penjajakan di pasar yang tidak memperhatikan sanitasi dan higiene. Mitchell (2013) dalam penelitiannya melaporkan bahwa temperatur dan lama waktu penyimpanan dapat memengaruhi peningkatan jumlah bakteri E. coli pada ikan layang.

Angka cemaran mikroba yang ditemukan pada ikan layang segar belum melampaui standar mutu mikrobiologi ikan segar yaitu $5 \times 10^{5} \mathrm{CFU} / \mathrm{g}$ (BSN 2006). Penelitian ini sejalan dengan hasil penelitian Puri (2016) bahwa ikan tongkol (Euthynnus affinis) segar di Kota Bandar Lampung yang menemukan total bakteri juga dibawah batas SNI $\left(6,5 \times 10^{4}\right.$ CFU/g). Total bakteri (TPC) pada ikan layang yang diambil dari pasar Arumbae dan Batu Merah masih memenuhi standar mutu sehingga masih layak untuk dikonsumsi. Tetapi apabila penanganan ikan tidak dilakukan dengan baik maka kemungkinan ikan layang tersebut tidak dapat bertahan lama, karena sampai pada saat penjualan ikan di pasar jumlah mikroba sudah pada batas maksimum mikroba pada ikan segar yaitu $5 \times 10^{5} \mathrm{CFU} / \mathrm{g}$. Umumnya pedagang menyimpan ikan yang diambil pada pagi hari di dalam coolbox berinsulasi plastik dan tidak tembus dengan perbandingan es dan ikan (1:1), kemudian akan dijual kembali pada sore hari. Proses penanganan ikan segar dilakukan dengan cara pendinginan. Perbandingan ikan dan es sangat mempengaruhi keberadaan mikroba selama penyimpanan. Hal ini sesuai dengan hasil penelitian yang dilaporkan Mile (2013) ikan layang yang diberi pengesan dengan perbandingan ikan dan es, 1:2 selama 
penyimpanan hari ke-0 sampai hari ke-6

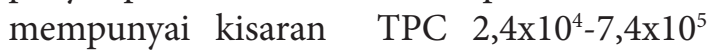
$\mathrm{CFU/g}$, sedangkan total bakteri psikrofilik yaitu $8,2 \times 10^{3}-3,9 \times 10^{5} \mathrm{CFU} / \mathrm{g}$. Salah satu cara untuk meminimalisasi tingkat kontaminasi bakteri pada ikan yaitu dengan menjaga kebersihan tempat penyimpanan ikan dan penggunaan es yang cukup. Affandi et al. (2016) menjelaskan bahwa jumlah mikroba pada ikan tongkol (Euthynnus affinis) yang dijual di TPI Lampulo yaitu $\left(8,8 \times 10^{3} \mathrm{CFU} / \mathrm{g}\right)$ lebih kecil dari ikan yang dipasarkan oleh penjual ikan keliling di Kota Banda Aceh (1,1x107CFU/g). Rivai (2014) menjelaskan bahwa contoh ikan tongkol yang dipasarkan oleh pedagang keliling di Kota Makassar menunjukkan angka lempeng total tidak melebihi dari $5 \times 10^{5}$ CFU/g. Adanya perbedaan angka cemaran mikroba ini dimungkinkan oleh manajemen sanitasi dan penyimpanan selama penjajakan ikan yang tidak antara pedagang tersebut.

Berhimpon (1993) menjelaskan bakteri proteolitik Gram negatif yang menyebabkan kebusukan ikan biasanya tumbuh pada suhu rendah, di antaranya Pseudomonas spp, Acinetobacter, Moraxella, Flavobacterium, Vibrio dan Coliform. Selain itu tingginya jumlah mikroba yang terdapat pada ikan layang juga dipengaruhi oleh kondisi daging ikan yang banyak mengandung nutrien, suhu dan $\mathrm{pH}$ sehingga cocok sebagai media yang baik untuk pertumbuhan bakteri (Mile 2013).

\section{KESIMPULAN}

Teknik penanganan dan penjajakan ikan layang yang diterapkan oleh para pedagang di Pasar Arumbae dan Batu Merah belum diterapkan dengan baik dan belum memperhatikan sistem rantai dingin, sanitasi air, tempat penyimpanan ikan selama penjualan. Jumlah cemaran mikroba pada ikan layang yang dijual di pasar tradisonal Kota Ambon masih memenuhi Standar Nasional Indonesia dengan maksimum cemaran bakteri pada ikan segar

\section{DAFTAR PUSTAKA}

Affandi RP, Ferasyi TR, Karina S, 2016. Uji mikrobiologi ikan tongkol (Euthynnus affinis) yang didistribusikan di tempat pelelangan ikan (TPI) lampulo dan oleh pedagang ikan keliling (PIK) di kota banda aceh. Jurnal Ilmiah Mahasiswa Kelautan dan Perikanan Unsyiah. 1(3): 318-324

Afrianto E, Liviawaty E. 2010. Penanganan Ikan Segar. Bandung (ID) : Widya Padjadjaran.

Andiny P. 2017. Analisis tingkat keuntungan pedagang ikan di kecamatan peureulak kabupaten aceh timur. Jurnal Samudra Ekonomika. 1(1): 22-32

Apelabi PC, Wuri DA, Sanam MUE, 2014. Perbandingan nilai total plate count (TPC) dan cemaran Salmonella sp. Pada ikan tongkol (Eutynnus sp.) yang dijual di tempat pelelangan ikan (TPI), pasar tradisional dan pedagang ikan eceran di kota kupang. Jurnal Kajian Veteriner. 3(2): 121-137

Apituley YMTN, Bawole D, Savitri IKE, Tuapettel F. 2017. Pemetaan rantai nilai ikan pelagis kecil di kota ambon. Jurnal PAPALELE . 1(1): 15-21

Apriani R, Ferasyi R, Razali R. 2017. Jumlah cemaran mikroba dan nilai organoleptik ikan tongkol (Euthynnus affinis). Jurnal Ilmiah Veteriner. 1(3): 598-603

[BSN] Badan Standardisasi Nasional. 2006. Ikan Segar-Bagian 1. SNI 01- 2729-12006. Jakarta (ID) : Badan Standardisasi Nasional.

[BSN] Badan Standardisasi Nasional. 2006. Cara Uji Mikrobiologi. Penentuan Angka Lempeng Total (ALT) pada Produk Perikanan. SNI 01.2332.3-2006. Jakarta (ID) : Badan Standardisasi Nasional.

Berhimpon S. 1993. Mikrobiologi Perikanan Ikani. Bagian 1. Manado (ID): Universitas Sam Ratulangi

Dwiyitno. 2010. Identifikasi bakteri patogen pada produk perikanan dengan teknik molekuler. Jurnal Squalen. 5(2):67-78.

Hadiwiyoto S. 1993. Teknologi Pengolahan Hasil Perikanan Jilid I. Yogyakarta (ID) : Liberty 
Husni A, Putra MP. 2015. Pengendalian Mutu Hasil Perikanan. Yogyakarta (ID) : Gadjah Mada University Press.

Junianto. 2002. Teknik Penanganan Ikan. Bandung (ID) : Penerbit Swadaya

Kapisa NE, Timbowo SM, Mewengkang HW, 2014. Bakteri Escherichia coli pada air pencuci ikan di pasar bahu manado. Jurnal Media Teknologi Hasil Perikanan. $2(2): 68-70$

Kurniawan R, Dessy Y, Syahril N. 2012. Analisis Bakteri Pembentuk Histamin pada Ikan Tongkol di Perairan Pasie Nan Tigo Koto Tangah Padang Sumatra Barat. Riau (ID) : Universitas Riau.

Laksmi BJ. 1988. Sanitasi Dalam Industri Pangan. Bogor (ID) : Penerbit Kanisius bekerjasama dengan Pusat Antar Universitas Pangan dan Gizi, IPB Bogor.

Litaay C, Wisudo SH, John Haluan J, Harianto B. 2017. Pengaruh perbedaan metode pendinginan dan waktu penyimpanan terhadap mutu organoleptik Ikan cakalang segar. Jurnal Ilmu dan Teknologi Kelautan Tropis. 9 (2):717-726

Metusalach, Kasmiati, Fahrul, Jaya I. 2012. Analisis hubungan antara cara penangkapan dan cara penanganan dengan kualitas ikan yang dihasilkan. [Laporan hasil penelitian]. Makassar (ID): LP2M. Universitas Hasanuddin.

Mile L. 2013. Analisis TPC dan total bakteri psikrofilik pada ikan layang (Decapterus macrosoma) selama penyimpanan suhu rendah. Nikè: Jurnal Ilmiah Perikanan dan Kelautan. 1(2): 103-106.

Mitchell LS 2013. Pengaruh suhu dan waktu penyimpanan terhadap peningkatan kadar histamin pada ikan tongkol. [Skripsi]. Gorontalo (ID) : Universitas Negeri Gorontalo.

Panai AS, Sulistijowati R, Dali FA. 2013. Penentuan perbandingan es curah dan ikan nike (Awaous melanocephalus) segar dalam coolbox berinsulasi terhadap mutu organoleptik dan mikrobiologis selama pemasaran. Jurnal Ilmiah Perikanan dan Kelautan. 1(2) : 59-64.

Pattipeilohy F, Moniharapon T, Apituley
YMTN. 2010. Penggunaan atung (Parinarium glaberimum, HASSK) pada penanganan ikan segar. Ambon (ID) : Universitas Pattimura.

Pattipeilohy F, Moniharapon T. 2016. Kualitas sensoris ikan layang (Decapterus macrosoma) segar pascatangkap dengan penggunaan ekstrak rumput laut jenis sayur karang (Gymnogongrus sp.). Majalah Biam. 12 (2): 20-26

Prihatminingtyas B, Setyowati PB 2018. Pengembangan pasar tradisional di kota malang. Conference on innovation and application of science and technology (CIASTECH 2018) Malang (ID) : Universitas Widyagama Malang.

Puri AA. 2016. Uji bakteriologis dan organoleptik ikan tongkol di pasar tradisional, modern dan gudang lelang Kota Bandar Lampung. [Skripsi]. Lampung (ID) : Universitas Lampung.

Rivai AA. 2014. Karakteristik mutu ikan tngkol (Auxis thazard) segar yang dipasarkan eceran keliling. [Skripsi]. Makassar (ID) : Universitas Hasanuddin

Sebayang N. 2002. Penerapan teknologi pengasapan ikan bagi masyarakat nelayan. Jurnal Pengabdian Kepada Masyarakat. $8(28): 25-34$

Sitakar NM, Nurliana, Jamin F, Abrar M, Manaf ZH, Sugito. 2016. Pengaruh suhu pemeliharaan dan masa simpan daging ikan nila (Oreochromis niloticus) pada penyimpanan suhu $-20^{\circ} \mathrm{C}$ terhadap jumlah total bakteri. Jurnal Medika Veterinaria. 10(2) : 162-165.

Susanto JP, Sopiah N. 2003. Pengaruh logam dan konsentrasi substrat terhadap pertumbuhan dan aktivitas bakteri proteolitik pada proses deproteinasi cangkang rajungan. Jurnal Teknologi Lingkungan. 4(1) : 40-45

Syafitri, Metusalach, Fahrul. 2016. Studi kualitas ikan segar secara organoleptik yang dipasarkan di kabupaten jeneponto. Jurnal Ipteks PSP. 3 (6): 544 - 552

Tapotubun AM, Savitri IKE, Matrutty TEAA. 2016. Penghambatan bakteri patogen pada ikan segar yang diaplikasi Caulerpa 
lentillifera. Jurnal Pengolahan Hasil Perikanan Indonesia. 19(3): 299-308

Violentina GAD, Ramona Y, Mahardika IGNK. 2015. Identifikasi bakteri dari ikan tongkol (Euthynnus affinis) yang diperdagangkan dipasar ikan kedonganan bali. Jurnal Biologi . 19 (2) : 58-62.
Winarni T, Swastawati F, Darmanto YS, Dewi EN. 2003. Uji mutu terpadu pada beberapa spesies ikan dan produk perikanan di Indonesia. [Laporan Akhir Hibah Bersaing XI Perguruan Tinggi]. Semarang (ID) : Universitas Diponegoro 